Anuario del Instituto de Historia Argentina, vol. 17, nº 1, e039, junio 2017.

ISSN 2314-257X

Universidad Nacional de La Plata.

Facultad de Humanidades y Ciencias de la Educación.

Centro de Historia Argentina y Americana

\title{
Ilustración española y economía política en la prensa rioplatense tardocolonial
}

\author{
Spanish enlightenment and political economy in the Press of the \\ late colonial Rio de la Plata
}

\section{Facundo Lafit*}

* CONICET - Universidad de Buenos Aires, Argentina | lafitfacundo@gmail.com

\section{PALABRAS CLAVE}

Ilustración española

Ilustración rioplatense

Prensa rioplatense

Economía política

Cultura política

\section{KEYWORDS}

Spanish enlightenment

Rio de la Plata’ enlightenment

Rio de la Plata’ Press

Political economy

Political culture

\section{RESUMEN}

Se busca indagar en la recepción, circulación y adaptación en el Río de la Plata tardocolonial del pensamiento ilustrado español, poniendo el foco en los primeros periódicos del virreinato: el Telégrafo Mercantil y el Semanario de agricultura. Se busca revelar la adaptación y usos que se dieron a los escritos de ilustrados peninsulares como Campomanes, Valentín de Foronda o Jovellanos en las producciones y discusiones de la incipiente ilustración rioplatense.

\begin{abstract}
This article studies the reception, circulation and adaptation in the late-colonial Rio de la Plata of the spanish enlightenment, focusing on the first newspapers of the viceroyalty: the Telégrafo Mercantil and the Semanario de agricultura. We propose to reveal the adaptation and uses that were given to the writings of peninsular enlightened as Campomanes, Valentín de Foronda or Jovellanos in the intellectual productions and discussions of the emerging Rio de la Plata' enlightenment.
\end{abstract}




\section{Apuntes iniciales}

En los últimos años la historiografía especializada considera que en el Río de la Plata, al igual que en el resto de la América española, existía un universo intelectual mucho más amplio y ecléctico que el que tradicionalmente se sostuvo en la antinomia ilustración francesa/neoescolástica española. Los trabajos de José Carlos Chiaramonte han echado luz en este sentido al destacar el papel desempeñado por la ilustración española y el derecho natural y de gentes en la conformación de la cultura política rioplatense de la época. Por otro lado, si nos remitimos exclusivamente al campo del pensamiento económico, son valiosos los aportes realizados por Rodolfo Pastore y Nancy Calvo, que reconocen una vinculación intelectual considerablemente más compleja que la simple adscripción a los conceptos de las escuelas fisiocráticas o la librecambista -como desde la historiografía tradicional siempre se afirmó-. Estos autores entienden que prevaleció una "amalgama de pensamientos diversos por encima del seguimiento exclusivo de algún enfoque económico en particular” (Pastore y Calvo, 2005), y destacan la atención puesta por los rioplatenses en las obras y debates de los economistas peninsulares. En el presente trabajo tomamos como punto de partida estas apreciaciones y, a partir de un estudio del conjunto de la prensa periódica de principios del siglo XIX, consideramos que las discusiones y planteos plasmados en los periódicos formaron parte del intenso proceso de circulación de saberes, discursos y prácticas culturales que atravesaron la ilustración hispánica, y que no sólo remitieron a temáticas económicas, sino al conjunto de las preocupaciones que, tanto de un lado del Atlántico como del otro, desvelaban a aquellas elites letradas convencidas de las posibilidades de progreso material y espiritual de la Monarquía española.

En la primera parte de este trabajo se aborda de manera panorámica el contexto rioplatense de principios de siglo XIX y el proceso de transformaciones que van permitiendo la aparición de una élite intelectual ilustrada y nuevos ámbitos de sociabilidad a nivel local. La segunda parte está destinada a revelar las marcas ilustradas en la prensa entre los años 1801 y 1807, y se pone el acento en las formas de adaptación y los usos que los publicistas locales dieron a los textos y las ideas de los ilustrados españoles como Campomanes, Foronda o Jovellanos, entre otros, en los dos primeros periódicos impresos rioplatenses: el Telégrafo Mercantil, Rural, Político, Económico e Historiográfico del Río de la Plata, y el Semanario de Agricultura, Industria y Comercio.

\section{La Ilustración en el Río de la Plata}

No se debe representar a la Ilustración como una marea que barrió las ideas precedentes. En general, en toda Europa fue un fenómeno parcial, y en el Imperio español con mayor razón por su relativo aislamiento y el peso de las ideologías tradicionales, respaldadas por una Inquisición debilitada, pero aún activa. Pero por necesidad y por urgencia, para sacar a España de su atraso, el movimiento que hasta ese momento se expresaba sólo en algunos núcleos desperdigados por la península, se fue convirtiendo en "política de Estado”. ¿Quiénes fueron aquellos ilustrados? Fueron los ministros y consejeros de Carlos III y Carlos IV, como Pedro Rodríguez de Campomanes, el conde de Floridablanca, Francisco Cabarrús y el conde de Aranda, los escritores como José Cadalso y Juan Meléndez Valdés, los sabios como Gaspar de Jovellanos y Antonio de Cavanilles, los economistas como Antonio de Capmany, Jordán de Asso y Pedro de Olavide. El primero de esos focos fue el asturiano, a partir de la actividad intelectual pionera del padre Benito Feijoo y, tiempo después, del Instituto creado por Jovellanos en su Gijón natal. Junto a este último, la otra gran figura destacable del Principado fue el conde de Campomanes, político, jurisconsulto y economista a cargo del Ministerio de Hacienda en 1760 durante el reinado de Carlos III (Domínguez Ortiz, 2005). Para estos ilustrados el fin supremo de la cultura era la eficacia, y la utilidad pública la meta sagrada. La instrucción práctica ampliamente difundida debía ocupar el sitio de la rutinaria enseñanza teórica. Para el despotismo ilustrado, cuyo lema era Todo por el pueblo, pero sin el pueblo, las luces debían irradiar desde lo alto. Existía un consenso total en que era el trono el que debía ser el dispensador y orientador de la cultura, porque 
únicamente su autoridad y poder podían llevar a buen término una empresa de tal envergadura. Sólo las grandes fuerzas organizadas eran capaces de recuperar el tiempo perdido. Estaban convencidos y confiados en devolver a España su grandeza, y ese entusiasmo estalló en los periódicos, en las sociedades económicas, e incluso en la poesía y las bellas letras (Sarrailh, 1974).

Con la creación del Virreinato del Río de la Plata en 1776, la consiguiente instauración de la Audiencia en 1785, y la erección del Consulado con sede central en Buenos Aires en 1794 se establecieron las bases de una estructura organizativa enmarcada en la política reformista de la metrópoli para la región y, al mismo tiempo, se convirtió a esta ciudad en el centro económico y político de una extensa y floreciente jurisdicción, de tierras muy fértiles, transportes fluviales y marítimos accesibles, así como en un puerto de ultramar que poco a poco iba tomando envergadura. Este es el contexto que fue propiciando y favoreciendo a principios del siglo XIX el surgimiento -en la capital- de una élite intelectual ilustrada, preocupada por dar cabida a la discusión de ideas económicas y conocimientos “útiles” y a la difusión de las "novedades”. De a poco fue irrumpiendo entonces una nueva práctica intelectual que impulsó la creación de espacios y escritos en los que las novedades científico-técnicas y las nuevas ideas económicas del Siglo de las Luces fueron adquiriendo matices locales. La figura paradigmática de Juan Baltazar Maciel, reformista canónigo de Buenos Aires educado por los jesuitas, refiere cómo al amparo del reformismo borbónico se difunden en el Río del Plata líneas de pensamiento innovador. Pero la generalización de esta actitud crítica se corresponde no sólo a las corrientes heterodoxas dentro de la Iglesia, sino también a la creciente laicización de la cultura rioplatense a fines del período colonial. Esto vale sobre todo para Buenos Aires, donde abundaban abogados y otros letrados laicos. Entendemos que, al igual que en España, se trata de un contexto cultural muy dinámico que recoge y combina elementos del "reformismo escolástico, el regalismo estatal hispano, el reformismo institucional dentro de la Iglesia, la ciencia y la filosofía del siglo XVII, y la Ilustración” (Chiaramonte, 1997).

En 1783 es inaugurado el Real Colegio Convictorio de San Carlos, por iniciativa del virrey Vértiz y bajo los

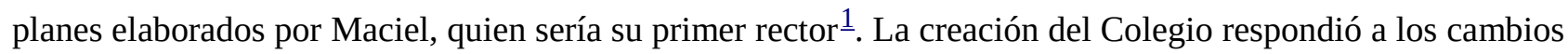
de orientación de los estudios que la Corona había dispuesto a ambos lados del Atlántico luego del destierro de los jesuitas, quienes habían ocupado hasta entonces un lugar central en las instituciones educativas

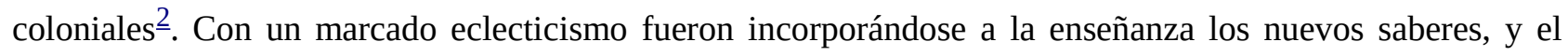
cuestionamiento -al menos parcial- del principio de autoridad fue el elemento más significativo. A la vez que se afianzaba el regalismo se promovía una moderada apertura a los progresos de la ciencia, y se renovaba también la enseñanza de la filosofía y la teología (Goldman, 2012)

Los viajes de estudio de los criollos a Europa también desempeñaron un papel importante de intermediación de los movimientos culturales. Los casos más sobresalientes a destacar por el papel pionero que desempeñaron son el de Manuel José de Lavardén entre 1770-1778, el del Deán Funes entre 1775-1779, y el más conocido de Manuel Belgrano, entre 1786-1793, todos en la península. De este último tenemos una interesante memoria para compartir:

Como en época de 1789 me hallaba en España y la Revolución de Francia hiciese también la variación de ideas, y particularmente en los hombres de letras con quienes trataba, se apoderaron de mí las ideas de libertad, igualdad, seguridad, propiedad, y sólo veía tiranos en los que se oponían a que el hombre, fuese donde fuese, no disfrutase de unos derechos que Dios y la naturaleza le habían concedido, y aun las mismas sociedades habían acordado en su establecimiento directa o indirectamente. Al concluir mi carrera por los años de 1793, las ideas de economía política cundían en España con furor y creo que a esto debí que me colocaran en la secretaría del Consulado de Buenos Aires... (Belgrano, 1945). 
Justamente desde su cargo en el Consulado, Belgrano promovió la instalación de academias -las de Náutica y Dibujo se fundaron ambas en 1799-, concursos y premios; y a través de las memorias anuales del Consulado, sus traducciones y escritos periodísticos, fue un pilar en la difusión del nuevo pensamiento económico en el Río de la Plata (Navarro Floria, 1989). Al igual que muchos de los ilustrados hispanoamericanos confiaba en el arbitraje del poder político sobre el despliegue de las fuerzas económicas para la transformación de la sociedad (Halperín Donghi, 1972). Precedida por esta actividad, la nueva etapa que se abría a comienzos del XIX estuvo marcada por la "aparición del periodismo como fenómeno estable, las iniciativas educacionales con fines utilitarios y elaboración de documentos políticos económicos y literarios de relevancia” (Chiaramonte, 1997). Las fuentes utilizadas variaron desde un principio de las fisiócratas francesas y neomercantilistas españolas al posterior reconocimiento de las neomercantilistas de los economistas o "filósofos” del Reino de Nápoles -Antonio Genovesi, el abate Galiani, Gaetano Filangieri, entre ellos- que fueron, también, una fuente importante para la obra de los españoles de la segunda mitad de siglo (Chiaramonte, 1997).

\section{La prensa ilustrada rioplatense}

Rezagado temporalmente en comparación con el resto de la prensa ilustrada hispanoamericana, y con la experiencia peninsular como espejo, el 1 de abril de 1801 ve la luz por primera vez el Telégrafo Mercantil, Rural, Político, Económico e Historiógrafo del Río de la Plata ${ }^{3}$. Nace fruto de la firme voluntad de Francisco Cabello y Mesa, un extremeño radicado no hacía mucho tiempo en la capital, que había hecho sus primeros pasos como periodista en España y que luego, en el Virreinato de Perú, editó la primera publicación diaria de Hispanoamérica ${ }^{4}$. Al igual que sus pares hispanoamericanos, el Telégrafo Mercantil se propone la divulgación de "las novedades" como uno de sus objetivos primordiales, y publica tanto noticias y artículos de opinión estrictamente económicos, como artículos que incluyen un abanico más amplio de materias consideradas "útiles" para el mejoramiento de la sociedad. Constitutivo y a la vez orientador de la embrionaria opinión pública rioplatense, el periódico forma parte de un proyecto pedagógico de corte ilustrado que ambiciosamente Cabello y Mesa intentaba encarnar en el Río de la Plata, y que contaba con el paraguas protector del Estado borbónico, preocupado en la difusión de estas cuestiones en todos los territorios bajo su dominio ${ }^{\underline{5}}$. Existe también una búsqueda, de éste y de alguno de los colaboradores del periódico, de reivindicar a América frente a la intelectualidad europea, hartos ya de que siguiera circulando y alimentándose la imagen de continente bárbaro e incivilizado.

La divulgación de las novedades de la llamada nueva ciencia experimental tiene un espacio importante dentro de sus páginas, a partir de la reproducción de artículos y noticias, no sólo con el objetivo de saciar la curiosidad ilustrada, sino sobre todo de perseguir las consecuencias "útiles" de su difusión. Esa intención la podemos emparentar con la prédica constante de Jovellanos a sus compatriotas a favor del estudio de

(...) aquellas ciencias que se llaman útiles por lo mucho que contribuyen a la felicidad de los Estados: (...) las matemáticas, la historia natural, la física, la química, la mineralogía y metalúrgica, la economía civil. Sin ellas nunca se podrá perfeccionar debidamente la agricultura, las artes y oficios ni el comercio (p. 452b).

Como sucedía en el conjunto del mundo hispánico, al Telégrafo se le hacía muy difícil escapar a los controles establecidos por la censura gubernamental para definir qué era lo publicable y qué no $\underline{6}$. En la Recomendación del censor Benito de la Mata-Linares, regente de la real audiencia, dirigida al Virrey Marqués de Avilés el 31/10/1800, podemos apreciar los límites de esta ilustración tutelada: 
(...) guardar moderación, evitar toda sátira, no abusar de los conceptos, meditar bien en sus discursos para combinar la Religión, Política, Instrucción y principios, a efecto de que no sea fosfórica la utilidad de este proyecto, sujetándolo a una censura fina, y meditada, que deberá sufrir antes de imprimirse... (Telégrafo, p. 6).

La transgresión de algunos de estos principios por parte de Cabello y Mesa, entre otras cosas, empujó a la caída en desgracia del periódico. La clausura del Telégrafo, ordenada por el virrey del Pino en octubre de 1802, se produce tras la publicación del artículo titulado "Política, Circunstancia en que se halla la provincia de Buenos-Aires e Islas Malvinas y modo de repararse”, cuya crítica a la sociedad porteña es considerada como demasiado corrosiva. Pero tal artículo fue en realidad la gota que rebalsó el vaso; la agonía había comenzado varios meses antes con intimaciones y quita de colaboraciones y suscripciones ${ }^{\underline{ }}$.

Aunque se puede presentar al Semanario de Agricultura, Industria y Comercio como el continuador del Telégrafo Mercantil en muchos aspectos, a diferencia de éste -que se planteaba abarcar una multiplicidad temática mayor-, el primero era menos heterogéneo en su contenido y se propuso inicialmente el tratamiento casi exclusivo de las materias económicas y, en particular, las relacionadas con la actividad agropecuaria ${ }^{8}$. Con Juan Hipólito Vieytes a la cabeza de la empresa editorial contó con la colaboración de varios de los letrados ilustrados de la capital virreinal, entre los que se destacaban Manuel Belgrano, Pedro de Cerviño, Gabriel de Hevia y Pando y Manuel de Lavardén $\underline{9}$.

En su prospecto se propone ser "el Órgano por donde se trasmitan al pueblo las útiles ideas de los compatriotas ilustrados que quieran tomar parte en ésta empresa”, y advierte que se abocará a cuestiones "de la agricultura en general, y los ramos que la son anexos", como así también de "todos los ramos de la industria que sean fácilmente acomodables a nuestra presente situación, del comercio interior y exterior de estas Provincias" (Semanario, pp. 5-7). Para el Semanario los párrocos rurales eran actores clave en la consecución de estos objetivos y por lo tanto se les reclamaba su colaboración en varios números. Se promueve desde el periódico que se conviertan en difusores - en las campañas bonaerenses- de los adelantos y novedades técnicas tendientes a la mejora de la agricultura y otros oficios en el Virreinato. El ser prácticamente los únicos letrados en ese medio, los convertía en el canal casi exclusivo para llegar a las poblaciones rurales, en sintonía con la política regalista de los borbones (Martínez, 2009). Foronda en su Cartas recomendaba el fomento del gusto por la lectura de "libros y diarios de agricultura" a las "gentes de conveniencias y a los señores Eclesiásticos”르. Como sugiere Martínez Gramuglia (2012), ambos periódicos, tanto el Telégrafo como el Semanario, definían su lector ideal como un sujeto débil, alejado del ideal ilustrado, que en cierto modo necesitaba de la conducción de un letrado para entrar en su "mayoría de edad": mujeres, niños, jóvenes, labradores, campesinos, analfabetos.

\section{La Economía Política}

Al igual que con otro tipo de obras, las de economía política llegaban al Río de la Plata desde Europa por diferentes vías: a través de los libreros locales, por encargo a residentes en la Península, por viajes de estudios, o por los que realizaban los funcionarios de la administración virreinal y los eclesiásticos (Fernández Armesto, 2005)ํㅗㄹ . La mayoría de los libros de economía con cierta trascendencia contó con una versión en español, adaptada en muchos casos a las necesidades del país y de la censura, de manera que ciertos libros originales prohibidos tenían su versión española "lícita”트. En principio, las obras de economía sorteaban más fácilmente las sospechas de peligrosidad, en gran medida porque ésta comenzaba a perfilarse como ciencia amparada en el prestigio de la Ilustración y encuadrada en una dimensión utilitaria. Según un estudio realizado a partir de los inventarios de las bibliotecas rioplatenses de la época, es destacable el 
predominio de obras de economía política de autores españoles como Campomanes o Ward, lo cual es sumamente lógico en el marco del proceso de circulación cultural del mundo hispánico al que venimos haciendo referencia y el carácter "mediador" de las ideas en boga en los centros de conocimiento europeos que poseían estas obras. $\frac{13}{}$ El historicismo tan característico en ellos y su atención a las condiciones particulares de la monarquía hispana eran dos atributos muy atractivos para los rioplatenses. Notable es también la presencia de los economistas y juristas napolitanos en las bibliotecas, aspecto ya señalado por Chiaramonte en sus trabajos sobre la ilustración hispanoamericana y profundizado recientemente por las investigaciones de Federica Morelli. Sorprende sí, como menciona Fernández Armesto, la ausencia de obras de Jovellanos, pero a partir del análisis de los artículos tanto del Semanario como del Telégrafo -que realizamos a continuación en este trabajo- podemos suponer que fue asidua lectura del grupo ilustrado rioplatense.

Desde las páginas del Semanario, Lavardén, con el seudónimo anagramático de Juan Anselmo Velarde, reconocía la ventaja de consultar las obras de los pensadores extranjeros en materia económica, pero a la vez advertía sobre las grandes diferencias que separaban al virreinato rioplatense de naciones como Francia o Inglaterra. Consideraba que: "Nos servirán los principios generales de la ciencia económica. El descenso a lo particular debe ser todo nuestro, porque no tenemos quién nos dé el ejemplo” (Semanario núm. VII, 3/11/02, p. 50). En el artículo, Lavardén enumera entonces las particularidades de la región, que según él demandaban originalidad a la hora de la reflexión teórica.

En mayo de 1804, el Semanario publica una carta, probablemente del propio Vieytes, donde se aboga a favor de la exportación de los frutos de país. Una vez más se vuelve a hacer referencia a la nueva ciencia económica y las distintas teorías discutidas al otro lado del Atlántico. Propone tomar en cuenta el pensamiento de los sabios de Europa "no porque lo digan ellos, sino que se amalgaman admirablemente con la razón y la experiencia” (Semanario núm. LXXXVIII, 23/5/04, p. 299). Finalmente va a transcribir un largo texto de Valentín de Foronda sobre el cultivo y comercio de los granos, en el que el vasco ponía en un lugar de privilegio a esta nueva disciplina:

Tampoco son favorables las providencias que han tomado los gobiernos con la saludable mira de ahuyentar la hambre, lo que no es estraño, porque la ciencia de la economía política es todavía mas nueva que la física experimental, y asi como se desatinaba antes del descubrimiento de esta llave de la naturaleza quando se quería explicar las auroras boreales, el ascenso del agua en una bomba, los truenos, \&c. igualmente se han descarriado del verdadero camino los gobiernos que se han dexado conducir por una turba de politicastros que decidía descaradamente sobre materias que no se podían comprehender antes del nacimiento de la ciencia económico-política (p. 299).

La carta finaliza pidiendo que se continúen difundiendo entre los compatriotas las ideas de este "sabio Español" y de todos aquellos "sublimes políticos que tengan una conocida relación con nuestras circunstancias y situación” (p. 304). En 1806, Vieytes vuelve a destacar la figura del vitoriano, entre otros economistas y pensadores europeos que invita a estudiar:

¡Quanto desear que nuestros ciudadanos se empapasen en [los principios de la economía política] leyendo á este propósito a Ustáriz, Zabala, Campillo, Jovellanos, Foronda, \&c. entre los nacionales; y Galiani, el Marques de Miraveau, al Hombre de Estado, y sobre todo al sublime economista Adan Smith, entre los Extranjeros (Semanario núm. CCXI, 24/10/06, p. 114). $\underline{14}$

\section{Agricultura, comercio e industria}

La agricultura era considerada, tanto desde el Telégrafo como desde el Semanario, la actividad central en la que debían enfocarse tanto los esfuerzos de las autoridades virreinales, como del conjunto de la sociedad 
rioplatense en pos de potenciar al máximo el desarrollo económico en la región $\frac{15}{}$. Cabello y Mesa, en el prospecto del periódico que edita, la define como el "nervio principal de los estados", a la vez que afirma que el país "por su naturaleza debe ser agricultor y comerciante” (p. 14). Por su parte, también en el prospecto, pero en este caso del Semanario, Vieytes la pondera como "la base de las sociedades, la que alimenta a los Estados y la que hace a los hombres sencillos” (p. 3). En su primer número, dedicado íntegramente al tratamiento de la agricultura, el editor la ubica por encima del resto de las artes, incluidas la industria y el comercio. Y en lo que será una constante a lo largo de este tipo de proclamas que priorizan el desarrollo agrícola hace referencia a la ventaja comparativa que implica la enorme riqueza del suelo local:

(...) las inagotables minas del Cerro del Potosí, los riquísimos criaderos de aquellas trazas enormes de plata masiza que ha dado Guntajaya, ni los poderosisimos planes de oro del Rio Tipuani; serán nunca comparables con el inagotable tezoro que pueden producir nuestros dilatados Campos (p. 5).

Otro argumento que se repite en varios escritos del Semanario, y que tiene una clara resonancia del pensamiento ilustrado español -fundamentalmente de la obra de Jovellanos- es concebir a la agricultura no sólo como una herramienta para el progreso material, sino también como una herramienta de regeneración moral, un arma contra los vicios de la ciudad: "huirá de nuestros hogares la ociosidad, y la olgazaneria que trahe consigo aquellos vicios vergonzosos que degradan á la razón” (p. 5).

La unión entre el hombre ilustrado de la ciudad y el labrador de la campaña es otro de los principios sostenidos recurrentemente en las páginas de la prensa rioplatense de principios de siglo. Se considera que sólo a través de este vínculo los adelantos en la técnica llegarán a conocimiento del que trabaja la tierra “cuando el hombre ilustrado se le acerque y le ponga a la vista las mejoras que ignoraba, entonces conocerá en la práctica el Aldeano, el bien que reporta desprenderse de su bárbara costumbre...” (Telégrafo núm. XVIII, 30/5/01, p. 173). Esa misma orientación la podemos encontrar con insistencia en el Informe sobre la Ley agraria de Jovellanos: "La agricultura no necesita discípulos doctrinados en los bancos de las aulas ni doctores que enseñen desde las cátedras”, necesita, en cambio, “de hombres prácticos y pacientes que sepan estercolar, arar, sembrar (...), cosas que distan demasiado del espíritu de las escuelas y que no pueden ser enseñadas con el aparato científico” (pp. 122b-123a) $\underline{16}$.

Es indiscutible la circulación del pensamiento fisiocrático entre los letrados del virreinato. Sin ir más lejos, el propio Manuel Belgrano fue uno de los principales difusores de la fisiocracia en el mundo hispánico, hecho sobre el cual dan cuenta, entre otras cosas, las traducciones al castellano de algunas obras de esta escuela de pensamiento $\underline{17}$. Tanto él como el propio Vieytes cumplieron con uno de los papeles distintivos del publicista de la época: ser traductor cultural, mediador entre dos códigos diferentes (Martínez, 2012). Aun así, a partir del estudio del Telégrafo y del Semanario, podemos percibir una amplitud de lenguajes y enfoques sobre asuntos puntuales que excedían a la doctrina fisiocrática $\frac{18}{}$. Aunque la agricultura prevalecía en la consideración de la ilustración rioplatense como la principal actividad económica, no era entendida como la única generadora de riqueza; y tampoco por los reformistas metropolitanos. Pero al igual que en otros aspectos, esta cercanía con el pensamiento de la ilustración peninsular va a estar matizada por "las diferencias que imponían las restricciones comerciales del sistema colonial y por las particulares condiciones del gran potencial de riqueza natural de la región” (Pastore y Calvo, 2005).

Íntimamente ligado a la actividad agropecuaria, el comercio en el Río de la Plata era concebido como el imprescindible complemento para el desarrollo económico y social de esas provincias. El editor del Telégrafo publicó en los primeros números un artículo con el título de Idea General del Comercio de las Provincias del Río de la Plata, donde se define al comercio como aquello que "principalmente influye en la prosperidad de los Reynos y Pueblos” (Telégrafo T. I, núm. III, 8/4/01, p. 17). En el artículo se destacan las bondades naturales de estas provincias y cómo éstas se potenciarían con un comercio fuerte. Aunque no se 
refieren directamente ni a la Corona ni a la metrópoli, se recrimina a quienes sólo se dedicaban a buscar oro y plata en las "Provincias Argentinas". El autor se lamenta de la falta de decisión para encarar el desarrollo de otros ramos de la economía como eran la pesca, la salazón, las curtiembres, etc. Considera imprescindible vincular el puerto con las potencias europeas y potenciar de esa manera el comercio de la región, lo que según él, redundaría en beneficio de las arcas del estado. Esta leve insinuación de una política más flexible en lo comercial es parte de una crítica cada vez más frecuente en el debate local al mercantilismo, asociado a la realidad de postergación económica en el Río de la Plata.

En el Semanario también encontramos varios artículos que le otorgaban al comercio un lugar preponderante. En el número del 8 de octubre de 1802, en la nota con el encabezado de "Comercio", su autor cita a Montesquieu para subrayar la relación existente entre el comercio y las suaves costumbres de las naciones que lo practican. Más adelante, el 10 noviembre del mismo año, aparece un nuevo artículo donde se explicita el planteo que promueve liberar las trabas a la exportación, lo que da curso al comercio de los productos de la tierra. Tanto Jovellanos en su Informe sobre la Ley Agraria como Campomanes en sus Reflexiones sobre el Comercio Español a Indias (1762) abogaban por la liberación de las trabas al comercio de granos, pero es Valentín de Foronda quien quizás mejor representa el espíritu librecambista del pensamiento ilustrado español. En este sentido, volvemos a hacer referencia a la carta del núm. 88, que sería del propio Vieytes, en la que se consideraban las "indecibles ventajas que resultarían a la agricultura y comercio del Río de la Plata por una exportación continua y libre de los frutos del país”, materia que forma parte de las preocupaciones recurrentes del editor, y que encuentra en Foronda un vocero privilegiado para su causa:

(...) que no se prohiba la entrada ni la salida, que se dexe subir ó baxar el precio á proporción de las causas que producen la variación, que goce el comercio de trigo de una entera libertad, y salen fiadores de que se escapará de nuestro horizonte el expectro horrible de la hambre del mismo modo que se disipa la niebla al salir el Sol... (Semanario núm. LXXXVIII, 23/5/04, p. 303).

Por su parte, Jovellanos entendía que sólo la libertad de comercio interior podía ayudar a corregir los desequilibrios productivos de las distintas provincias, aunque hacía una excepción al permitir la injerencia del estado en el mercado en momentos en los que era un imperativo político conseguir granos para mantener el orden público, con la posibilidad de proceder temporalmente a tasas o requisas forzosas $\underline{19}$.

Aunque es evidente que para el grupo ilustrado rioplatense la prioridad estaba puesta en el desarrollo agrícola, no son pocas las veces en que se manifiesta a favor del fomento de la industria y otros ramos de la economía. Una de las primeras voces en este sentido la encontramos en el Telégrafo núm. 18, donde Ennio Tullio Grope -anagrama de Eugenio del Portillo, colaborador regular del periódico- critica el artículo de Cabello y Mesa del Telégrafo del 27/5/01 titulado "Rasgo político-moral sobre contrabandos”, en el que entiende que el contrabando no era un problema moral, sino de economía política. Afirma, amparándose en los reformistas ilustrados, que:

(...) siempre ha de subsistir el exceso considerable de Contrabando, mientras no se aumente la población, se mejoren con ellas las fábricas, las manufacturas, y toda especie de industria popular en la nación hasta el grado de poder surtir sus dominios y repulsar la concurrencia por las reglas de los SS Campomanes, Cabarrús y el Abate Genovesi (p. 444).

El Semanario ya en su segundo número dedica un largo artículo al problema de la industria. El mismo parte del lugar central de la agricultura, pero se aboga para que los brazos sobrantes deban canalizarse a la industria doméstica. Ancianos, mujeres y niños debieran ocupar sus esfuerzos en estas tareas, lo que no sólo redundaría en un progreso económico para el núcleo familiar, sino para la sociedad entera. Se avanzaría además, en el propósito de desterrar el vicio del ocio y en la mejora en las costumbres. Para reforzar su argumentación cita a un “dedicado y zeloso patriota” español: 
Labradores: Nación alguna puede prosperar sin el fomento de la industria: su extensión es inmensa, sus objetos inumerables, sus utilidades indecibles. Quanto producen los tres Reynos de la naturaleza, tanto es susceptible de industria, y quanto abraza la industria tanto es útil á los hombres. Ella da ocupación y sustento á un sin numero de familias: ella atrahe la abundancia y las riquezas: ella aumenta la población y los consumos: ella destierra la pobreza y la mendicidad; ella promueve la ciencia, y las artes; ella vivifica las Naciones, y sin ella jamás pueblo alguno pudo salir de pobre, bárbaro, e ignorante: sin ella casi de nada sirve la agricultura, porque ella es la que da valor á los frutos que cultiváis, y la que da ocupación y provecho a los deviles brazos de vuestra familia numerosa (p. 10). $\underline{20}$

Estas reflexiones forman parte de una opinión de la época que juzga como uno de los problemas sociales más graves la "ociosidad" de la población; la misma opinión está presente en los trabajos y discursos de muchos economistas españoles, particularmente en Campomanes.

La idea de recobrar la grandeza nacional de España era otra de las inquietudes presentes en los artículos y cartas que promovían el desarrollo industrial de la nación española. En carta al Semanario, Lavardén se lamenta de la decadencia a la que han llevado a la industria española la entrada indiscriminada de productos extranjeros mientras el Imperio se adormecía con la plata y el oro americanos $\underline{21}$.

Como hemos podido observar, los escritos en la prensa rioplatense de principios de siglo pusieron el foco en el desarrollo de la agricultura como la clave para el despegue económico y social de la región, fundamentalmente por las ventajas naturales que ésta poseía, pero eso no implicaba que no se depositaran expectativas en otras actividades como el comercio o la industria, a las que se las entendía como complementarias de la primera y con posibilidades de una dinamización recíproca.

\section{La fe ilustrada en la educación}

La cuestión de la educación, tanto técnica como moral, se convirtió en un tema recurrente del Telégrafo Mercantil. En sus primeros meses se publicaron una serie de artículos que hacían referencia tanto a la educación doméstica como a la instrucción pública. Se reproduce, por ejemplo, en el número 13, un artículo extraído de la Historia antigua de México de Francisco Xavier Clavijero en el que un padre da recomendaciones sobre moral y conductas a su hijo (pp. 127-130). Más adelante será el turno de la educación pública, con un extenso artículo repartido en tres números consecutivos. En este fragmento se pueden percibir varias definiciones del tipo de educación a la que aspira el grupo ilustrado:

Cuando las escuelas y colegios se vean bien reglados, cuando la juventud reconozca superioridad y justos límites, cuando las leyes de estímulo puedan más que otras de temor, cuando un sabio plan económico y literario contraiga el entendimiento de los jóvenes, y menos distraídos en especulaciones fastidiosas y en morralla o bazofia literaria, sientan el buen gusto de sus adelantamientos; ¿por qué no deberemos esperar el remedio de las ciencias, el bienestar de nuestros patriotas, y si es posible, la gloria de la Religión y la felicidad del Estado? (Telégrafo T. I, núm. XVI, 23/05/01, pp. 123-124)

La fe en la educación, y en particular en la educación pública, fue siempre un componente clave del imaginario ilustrado, pero lo era aún más en la concepción de Don Gaspar de Jovellanos. Tanto es así, que en sus últimos años llega a la conclusión de que la principal fuente de la riqueza no era propiamente la agricultura -como hasta entonces había considerado- a la que situaba junto a la industria, el comercio y la población como fuentes secundarias. Para el asturiano, el origen primario de la riqueza radicaba en la educación, y en particular en la instrucción técnica: "la perfección del arte de aplicar el trabajo" (Llombart, 
p. 19). Esta cuestión la desarrollaría principalmente en la Memoria sobre la educación pública de 1802 y en las Bases para la formación de un plan general de instrucción pública de 1809, pero ya encontramos numerosos escritos a partir de 1796 en los que la cuestión educativa se vuelve el eje central de su pensamiento. En esos años, reflexionando en su diario sobre su querida Asturias afirmaba: "si no tiene buenas leyes las tendrá, porque éste debe ser un efecto infalible de la propagación de las luces. Cuando la opinión publica las dicte, la autoridad tendrá que establecerlas, quiera que no” (Jovellanos, p. 305). Y en la mencionada Memoria sobre la educación pública se pregunta: “ ¿Es la instrucción pública el primer origen de la prosperidad social? Sin duda..."

El fomento a la instrucción técnica era también una temática usual de los periódicos. A los artículos que difundían los adelantos y mejoras en la técnica, que eran aún más cotidianos dentro del Semanario que en el Telégrafo, se sumaban reflexiones y discursos que apuntaban al establecimiento de academias y otras instituciones que buscaban preparar a los habitantes del virreinato para las actividades productivas $\underline{22}$. Conocido es el discurso de Manuel Belgrano en los Certámenes Públicos de la Academia de Náutica, que se reproduce dentro de las páginas del Telégrafo, donde resalta la importancia de la formación de individuos útiles a la sociedad y se anuncian los alumnos premiados por su esmero y logros (Telégrafo T. I, núm. XII, 21/3/02, pp. 177-185) $)^{23}$.

Por su parte, el Semanario también dedicó varias entregas a la cuestión educativa, y en particular a la instrucción técnica. Tempranamente, en sus números 4 y 5, reproduce un artículo titulado "Educación Moral”, dirigido a los padres de familia de los sectores medios porteños, a los que increpa por no promover en sus hijos el estudio y la preparación en oficios. Se explica que esto se debe al prejuicio existente en este grupo social con respecto al "deshonor" que implicaba el trabajo de artesano $\underline{\underline{24}}$. Campomanes, en su Discurso sobre la educación popular de los artesanos, habla de estos prejuicios:

Ha sido grande error en política excitar cuestiones sobre la preferencia de las artes, y de los oficios: distinguiendo a unos con el dictado de liberales, y a otros con el de mecánicos. De ahí se pasó a hacer otra distinción de oficios bajos, y humildes; titulando a algunos de nobles. Estas denominaciones voluntarias y mal digeridas, han excitado repetidas emulaciones, y han sido parte, para que muchos abandonasen las artes, o apartasen a sus hijos de continuar en ellas, contra otra máxima general de hacer indirectamente hereditarios los oficios en las familias, para que los amen y perfeccionen (pp. 17-18).

Más adelante en este artículo del Semanario se plantea que sólo los hijos de familias muy acomodadas o aquellos que hayan mostrado un talento superior pueden dedicarse a los "estudios liberales", algo que se considera directamente prohibido para el bajo pueblo, donde los jóvenes no deben correr su atención del aprendizaje de los oficios (pp. 28-35). Podemos observar aquí nuevamente la recepción de la obra del ministro ilustrado, en este caso, de su Discurso sobre el fomento de la Industria Popular: "por fortuna es corto el número de los que deben dedicarse a las ciencias y ricos; en lugar que la industria Popular, de que trata este discurso, abraza la generalidad o mayor parte del pueblo" (p. 4).

\section{Lo "político" en tiempos de censura}

Ya hemos advertido que cuestiones que tocaran tanto lo político como lo religioso eran posibles objetivos de la censura gubernamental, y que por lo tanto es poco lo que encontramos dentro de las páginas de la prensa de principios del siglo XIX sobre estos temas. Aun así, mientras los escritos no estuvieran impregnados de una crítica directa al statu quo podían llegar a ser publicados. Hemos podido identificar algunos que nos sirven para definir ciertos rasgos de la cultura política rioplatense de la época que, como hemos afirmado ya, 
se trataba de un período transicional en el que varios conceptos políticos sufrieron una fuerte mutación de sentido, y en el que se produjo una compleja mixtura de elementos provenientes de diferentes tradiciones, lenguajes políticos y corrientes de pensamiento; en este período, además, entraron en contacto las nuevas doctrinas iusnaturalistas propias del Siglo de las Luces con los sustratos jurídicos y culturales hispanoamericanos, basados fundamentalmente en el derecho común y la neoescolástica.

Resulta aquí interesante hacer referencia al artículo de Cabello y Mesa "Rasgo político-moral sobre contrabandos", inspirado en un artículo del Espíritu de los mejores diarios europeos, pero aplicado a la realidad americana. El extremeño ataca obviamente la actividad del contrabando, y lo hace desde argumentos que exaltan el respeto tanto a la autoridad religiosa como estatal. Quien cometiera ese delito, dice, era a la vez "mal cristiano, mal vasallo y mal ciudadano". Los fundamentos utilizados remiten a una clara concepción absolutista sobre el origen de la autoridad del soberano: "El Supremo e independiente Legislador del Universo, la fixó en el trono y la sostiene. Así los reyes reinan por Dios y a su nombre establecen las Leyes". Cita también la doctrina del apóstol San Pablo: "El que resiste a la potestad resiste a la orden de Dios. No hay potestad que no emane de Dios. El súbdito ha de obedecer á su príncipe no solo por temor de la pena, sino también por los sentimientos de su conciencia” $\underline{25}$. Conociendo la trayectoria de Cabello y Mesa, entendemos que dichas posturas no son precisamente una declaración de fe. Aún lejos de las posiciones de un liberalismo apenas embrionario en el mundo hispánico, sí podemos caracterizar al pensamiento del periodista aventurero como de un regalismo moderado, más cercano al de los reformistas ilustrados peninsulares. Entonces, esta exaltada proclama absolutista se explica mejor, creemos, por la necesidad que tenía el autor de congraciarse con las autoridades virreinales, más aún si se tiene en cuenta el recurrente oportunismo que lo caracterizó a lo largo de su vida.

En el Semanario encontramos una carta de Lavardén interesante por su riqueza conceptual, orientada a discutir las visiones que se tienen desde el extranjero, fundamentalmente desde Inglaterra y Francia, sobre la situación económica que atraviesa España. Entiende que estos escritores, en general "nos denigran para disimular la ignorancia en que están de nuestras cosas”. Se dedica a rebatir entonces sus argumentos y ante la acusación de que en España se enseñorea el despotismo monárquico, Lavardén hace gala de fundamentos anclados en el constitucionalismo histórico para contrarrestar aquellas posiciones:

Despotismo no hay en donde hay un código legal. Habrá arbitrariedad no despotismo. Reynal creeria que sucedía en España lo que en Francia, en donde se gobernaban con ignominia de su decoro, por el derecho escrito de los Romanos, y por los fueros de las provincias que llamaban droit contumier. Los Españoles han tenido la mania de los Atenienses, cuyo Legislador quiso arreglar hasta los concubitos: ha mucho que España tiene Leyes fundamentales, que jura su Rey en su inauguración. Leyes fundamentales son las que hoy mas á la moda se llaman constitucionales. Algunos creen que no tenemos constitución, porque cumpliéndose con exactitud no hemos tenido nunca motivo de hablar de ella. Por lo que hace á la administración de justicia y gobierno político son tantas que ya clamamos por su reduccion. Una sola Ley no conocemos, que es la Ley marcial, y que yo no sé como han amalgamado los Ingleses con su decantada libertad. Supongo que la introducción de los Lores en la cámara de los comunes, y la prohibición de que estos tengan voto en la de los Pares, ya insinúa que aquel Pueblo está sabiamente alucinado (Semanario núm. XI, 1/12/02, p. 85). $\underline{26}$

El constitucionalismo histórico tuvo su entrada en la palestra del debate público en el mundo hispánico a partir del discurso de ingreso que Jovellanos presentó ante la Real Academia de Historia en 1780, titulado "Sobre la necesidad de unir el estudio de la legislación al de nuestra historia”. Para el asturiano, el conocimiento de la historia del derecho público nacional era fundamental para pensar en una constitución para la Monarquía. Mientras que en España la literatura económica y social era riquísima, las obras 
dedicadas al derecho público podían contarse con los dedos de las manos. No existía una obra que recogiera los hechos y noticias relativos a la historia de su derecho. En momentos de la crisis monárquica abierta con las abdicaciones de Bayona, esta misma perspectiva será utilizada por el liberalismo gaditano para legitimar una constitución que equilibre las prerrogativas de la soberanía real $\underline{27}$. Para los doceañistas se tratará de recobrar las libertades perdidas de un pasado idealizado y elevar unas nuevas cortes basadas en la soberanía popular y la representación nacional, aun cuando las cortes planteadas por Jovellanos mantenían el tradicional carácter estamental. Los españoles ilustrados antes de 1789 no protestaron nunca contra la falta de convocatoria a Cortes de los Borbones. Nadie hablaba en España de despotismo o de absolutismo. Los hombres de la minoría ilustrada estaban convencidos de que vivían en una monarquía moderada (Sarrailh, pp. 578-582). En todo caso, los escritos de Jovellanos jugaron un papel importante en el ámbito del naciente constitucionalismo americano, fundamentalmente en la obra del novohispano Servando Teresa de Mier, pero, como pudimos observar, también en la de letrados rioplatenses como Lavardén.

Por otro lado, quizás no en el orden estrictamente de "lo político", empiezan a aparecer en la prensa rioplatense artículos que someten a la crítica a algunos aspectos de la sociedad colonial. En el Semanario núm. 64 -7/12/03- se publica la carta de un supuesto preso llamado Julián Topio al editor, en la que denuncia la penosa situación en las cárceles de la ciudad, seguida de una reflexión del editor en la que se solidariza con la situación de los presos. En realidad, Julián Topio sería el anagrama -práctica habitual de la época- de Juan Ipolito, por lo tanto el autor de la carta, como de la respuesta, no sería otro que el propio Vieytes. Manuel Fernández López, en su trabajo Cartas de Foronda: su influencia en el pensamiento económico argentino, llama la atención de las similitudes entre la "Carta dirigida al Editor desde la cárcel de esta ciudad” y algunos fragmentos de las "Cartas” del vitoriano. Mientras en el Semanario se decía que la cárcel se ha establecido únicamente para "guardar con seguridad los delinquentes hasta el esclarecimiento de sus causas, que la desgracia debe ser siempre respetada, y que hasta la convicción el acusado no es sino un desgraciado" (p. 108); en la carta de Foronda leemos:

“Tenga Vmd. Presente que las cárceles no tienen otro objeto que el resguardo de los que están indiciados de algún crimen: así se les debe encerrar en un lugar sano, bien ayreado, y proveerles de todo lo que necesiten. De ningún modo se les deben...mortificarlos con otras vexaciones de esta naturaleza: es preciso recomendar á los carceleros que no traten duramente á los presos; pues la desgracia debe ser siempre respetada, y hasta la convicción, el acusado no es sino un infeliz”. $\underline{28}$

Otro artículo en el que podemos percibir aquel rasgo humanista tan caro al espíritu de los ilustrados es la carta de Gabriel de Hevia y Pando titulada justamente "Humanidad” del Semanario núm. 65 del 14/12/03, en la que se denuncian las insalubres condiciones a las que se veía sometido el trabajo de los indios en las minas del Potosí y los altos índices de la mortandad e infertilidad que esta situación estaría provocando entre los mitayos. El escrito llama la atención por el elevado tono de crítica a una realidad social tan compleja que formaba parte del mismo corazón del sistema de explotación de la metrópoli sobre los recursos americanos, tanto humanos como materiales. Por eso, no parece tan extraño que el "se concluirá..." con que cierra abruptamente el artículo no se concrete al número siguiente ni en los que lo sucedieron. En realidad, lo que sucedió fue que la segunda parte de la carta fue finalmente impresa en el número 66 del Semanario, luego de superar curiosamente el control del censor, pero cuando ya se hallaba listo para su distribución llegó la orden del virrey censurando el polémico artículo. El número tuvo que rehacerse y existieron dos tiradas del mismo: una permitida, y la otra prohibida y con destino de hoguera, cosa que no sucedió por lo menos para algunos ejemplares que circularon y fueron conservados en colecciones privadas (Díaz, 2012). En ese sentido, se entiende que unos meses después, en marzo del año siguiente, se haya incluido un artículo del editor en el que se plantea que lo denunciado sobre la situación en Potosí adolecía de actualidad, y en el que se asegura que el gobernador Paula Sanz se había preocupado por que las condiciones en los ingenios fueran lo más 
benignas posibles, por lo que había llevado adelante importantes reformas durante su gobierno (p. 219). A pesar de esta "aclaración”, volvemos a insistir en lo destacable de la crítica social, y en definitiva política, que implicó el artículo, que constituyó uno de los primeros antecedentes de esta clase en la prensa rioplatense.

Varios años antes de la prohibición de la introducción de esclavos y del decreto de libertad de vientres promulgado por la Asamblea del año XIII -que lo tuvo como uno de sus protagonistas-, Vieytes ya abogaba desde el Semanario por estas mismas causas: "proscribase para siempre este funesto trafico que causa indispensablemente perjuicios tan enormes a millares de hombres, que al mismo tiempo sirven de oprobio a la sociedad, perpetúan la pobreza y la miseria de America”. (Semanario núm. 186, 9/4/06, p. 258). La posición del publicista criollo no sólo respondía a ese espíritu humanista ilustrado del que hablamos, era también un elemento importante en su concepción económica en la que las artes y oficios debían ser patrimonio exclusivo de "hombres libres", desprovistos de cualquier tipo de sujeción.

\section{Consideraciones finales}

Aun con cierto rezago y una moderación mucho más acentuada, el iluminismo hizo impacto de manera indudable en el mundo hispánico. Con fuerzas poderosas enfrente -una clase nobiliaria conservadora, la Iglesia y su temible Inquisición-, la minoría ilustrada se las ingenió para ofrecerles pelea con el objetivo de encarrilar a España y su imperio en la "corriente civilizadora" que ya transitaban el resto de las potencias europeas. Despojada de un nacionalismo estrecho y a fin de cuentas poco productivo, consciente de que ya había pasado el tiempo de la hegemonía sobre Europa, y de que España no era ya sino "el esqueleto de un gigante”, se sumergió en las nuevas ideas que atravesaron el viejo continente.

América no fue ajena a este proceso, con España en el rol de mediadora de los debates y planteos de la ilustración europea. La presencia de los ilustrados españoles en las bibliotecas de los letrados y en los periódicos rioplatenses era una clara prueba de ello. Como ya dijimos, la ilustración española corría con ventaja entre los americanos por ofrecer una versión de las reformas más atenta a las condiciones particulares de la monarquía hispana. Los planteos tanto de Jovellanos como de Campomanes, Foronda y otros ilustrados partían de la necesidad de sacar a España y al conjunto del imperio del atraso en el que se encontraba y recuperar la grandeza perdida. Esta misma preocupación era compartida por las élites letradas americanas, quienes depositaron su fe, al igual que los peninsulares, en la mejora que traería aparejada el fomento de la educación pública y la instrucción técnica en la población. En definitiva, se trataba del intento de modernización, conflictivo en muchos casos, del espacio público de opinión bajo la lupa de los funcionarios de la Corona. Con una burguesía débil -en algunos casos, prácticamente inexistente- que cumpliera el papel de clase dirigente de la modernización capitalista, tanto en la península como en América, se buscó que fuera el Estado borbónico el que se pusiera a la cabeza del proceso de transformaciones sociales y económicas, en pos de recuperar el tiempo y el terreno perdidos. En el Río de la Plata era necesario atajar el deslizamiento que se venía produciendo de manera continua hacia la monoproducción ganadera. Como bien marcara Tulio Halperin Donghi (1961), los economistas ilustrados iban convenciéndose de que el juego automático de las fuerzas económicas no aseguraba la realización de sus ideales políticos ni éticos. Futuros dirigentes revolucionarios como Belgrano, inicialmente confiaron en que el gobierno virreinal iba a tomar las medidas modernizadoras reclamadas, cosa que sucedió a cuentagotas y que a fin de cuentas no generó más que desencanto entre los ilustrados rioplatenses. Entendemos que aquí radica una de las razones, entre otras, que explican que en el marco de la crisis monárquica varios de ellos buscaran replantear los términos de la relación con la metrópoli. En un mundo que ven desmoronarse frente a sus ojos se ven compelidos a interrogarse sobre sus funciones y sobre qué contribución podrían hacer a la constitución de un orden nuevo. Igualmente, principios de siglo no era tiempo aún de críticas directas por parte del grupo de "intelectuales” a 
las autoridades virreinales, ni tampoco al sistema colonial. Muchos de ellos formaban parte del gobierno, y la mayoría consideraba además que era posible perfeccionar el sistema "desde adentro", sin la necesidad de grandes sobresaltos. En su doble calidad de escritores-funcionarios, cumplieron una labor de propaganda de este ideario en particular, en algunos casos muy a tono con el conjunto de reformas administrativas. Si decíamos que en la península era difícil encontrar cuestionamientos de orden político o religioso por la censura o directamente porque no formaban parte del repertorio de los reformistas, en la prensa rioplatense esto fue aún más marcado. Lo "político" casi no tuvo lugar en los periódicos de principios del XIX; fue notoriamente menos expuesto que en los periódicos de la metrópoli. Hubo que esperar a la Gaceta de Buenos Aires, surgida al calor de la Revolución para poder identificar temáticas propiamente políticas. Lo que no significa que estos letrados no estuvieran en contacto ya con los lenguajes políticos que conmocionaban Europa.

Con respecto a la recepción de los debates económicos, tradicionalmente se consideró que los ilustrados rioplatenses abrevaban casi exclusivamente en el pensamiento fisiocrático o en el liberalismo smitheano. Los trabajos de Chiaramonte fueron pioneros en señalar la fuerte presencia de la "escuela napolitana" en los debates locales, y rompían por primera vez con esa imagen tradicional. Más recientemente, Pastore y Calvo han acertado al plantear que los argumentos agraristas tanto del Telégrafo como del Semanario no deben ser adjudicables a una axiomática filiación fisiocrática, sino que más bien hay que entenderlos como justificaciones conceptuales utilizadas para resaltar el papel del agro en desarrollo local, teniendo en cuenta las innegables ventajas comparativas de la región. Esto demuestra el proceso selectivo y de adaptación realizado sobre el pensamiento económico europeo, y particularmente español, por parte de la élite letrada rioplatense para aplicarlo a la realidad local. La recepción del pensamiento europeo en un medio local periférico como el Río de la Plata experimentó entonces un proceso de modificación conceptual y, lejos de ser una una simple copia o imitación, se produjo una "adopción correctiva de las ideas generadas en los centros de conocimiento de acuerdo a la percepción de las condiciones culturales y socioeconómicas que operan en el plano local” (Pastore, p. 13). A partir del análisis que hemos realizado de los periódicos podemos constatar que con los fisiocráticos se compartirá la importancia de la agricultura en la generación de riqueza, pero no su exclusividad. Con el liberalismo económico, los tibios pero cada vez más recurrentes planteos a favor de la libre exportación de los frutos, será a Foronda antes que a Smith al que citarán para reforzar sus argumentos. De los reformistas peninsulares puede observarse la convicción de que es el Estado el principal actor que debía intervenir sobre la realidad social para provocar o permitir las transformaciones necesarias en el camino de racionalización económica y social anhelada del imperio, incluidas aquellas que empiezan a colisionar con el sistema colonial, indiscutido por los metropolitanos.

La novel prensa rioplatense se constituyó entonces como la plataforma sobre la que la incipiente élite letrada porteña vehiculizó los debates y problematizaciones sobre la realidad socioeconómica del virreinato, y las posibilidades y opciones para transformarla. Y a la par, como sucedía en otros lugares de la América española, los periódicos cumplieron un papel destacado en el proceso difusor que había encarado la Corona. Con el contexto cultural hispánico de trasfondo, se produjo la incorporación de ciertos contenidos generales de la ilustración europea, y en particular la peninsular, a través de una receptividad que era a la vez un claro proceso de adaptación reflexiva, en el que las novedades científico-técnicas y las nuevas ideas económicas, entre otros temas ilustrados, fueron adquiriendo un "lenguaje local”.

\section{Notas}

$\underline{1}$ El célebre regente de los Reales Estudios se distinguía por su curiosidad intelectual, de la cual da elocuente prueba su "amplia y diversa biblioteca donde figuraban obras de teología, derecho canónico, jurisprudencia, filosofía, historia y letras de diversas corrientes intelectuales” (Goldman, 2012). Su domicilio era el hogar de 
una animada tertulia que reproducía la apertura intelectual que estaba ocurriendo en España en una escala mayor (Chiaramonte, 1989).

$\underline{2}$ Varios son los futuros protagonistas del proceso revolucionario rioplatense que pasaron por las aulas del San Carlos. Manuel Belgrano fue alumno de los cursos de filosofía de Chorroarín entre 1783-85 y con esta acreditación ingresó a estudiar leyes a la Universidad de Salamanca. Juan Vieytes participó de los cursos de Vicente Juanzarás entre 1775-77 y en el trienio siguiente en los de Carlos García Posse; Manuel Lavardén, cercano a Maciel y afín con sus ideas, pronuncia un discurso en los exámenes de filosofía en 1778; Juan José Castelli pasa por el colegio entre 1779-81 y Mariano Moreno entre 1793-95, antes de dirigirse ambos a sus estudios en Chuquisaca (Pastore y Calvo, 2000).

$\underline{3}$ En su corta vida se publicarán 110 de sus números, dos suplementos y trece ejemplares extraordinarios. Todos impresos en el único taller de la Ciudad-Puerto desde 1780, la Real Imprenta de los Niños Expósitos, relocalizada desde Córdoba a pedido del Virrey tras la expulsión de los jesuitas, con el fin de facilitar la impresión de papeles burocráticos, catones, catecismos y cartillas en todo el distrito del Virreinato.

4 El 1ero de octubre de 1790 publica -bajo el seudónimo de Jayme Bausate Mesa- el primer número del Diario de Lima, curioso, erudito, económico y comercial. Pero la firme competencia del Mercurio peruano, aparecido el 2 de enero de 1791 con el respaldo de la Sociedad de Amantes del País limeña, hizo tambalear su economía, lo cual determinó finalmente el cierre de su empresa periodística. (Martini, 1998).

$\underline{5}$ En el prospecto del Telégrafo, el editor manifiesta los objetos o ejes temáticos a los que se atendrá el periódico. En primer lugar lo "mercantil”, que incluye el comercio, la industria, el lujo y las artes. En segundo término lo "rural", que define a la agricultura como "el nervio principal de los estados". Lo "político-económico", que desarrolla lo que el autor entiende por política. Habla de la difusión de las "gacetas de nuestras cortes y otras papeletas que merezcan propagación” en el Virreinato. Finalmente destaca lo "historiográfico" y advierte el lugar preferencial que tendrá dentro del periódico por su "valor educativo y artístico” (pp. 12-15).

6 Seguimos a Cesar Díaz (2012) en que en teoría el sometimiento a todo impreso era inflexible, pero que "en la práctica se producían ciertas fisuras, posibilitadas por ocasionales complicidades entre los eventuales editores y censores, por las impericias o descuidos de estos últimos, o incluso, en la imposible circunstancia ( a priori) de la ausencia de censura. Todas ellas, propiciadas, de algún modo, por la permisividad de las altas autoridades, quienes evidentemente confiaban más en la autocensura de los propios directores y/o los colaboradores de los periódicos que en el control ejercido por sus propios funcionarios” (pp. 188-189).

$\underline{7}$ Dicho artículo, que en realidad se trataba de un plagio de un original de Juan de la Piedra de 1778, fue sólo uno entre varios que generaron controversias, no sólo con el gobierno virreinal sino en el seno de la emergente "esfera pública rioplatense”. Para algunos estudiosos el tono satírico y el lenguaje soez del poema aparecido un mes antes firmado con el seudónimo de El poeta médico de las almorranas ya había condenado a muerte al periódico (Díaz, 2012). Más detalles sobre la clausura del Telégrafo en Caillet-Bois y González (1941).

$\underline{8}$ Llegó a manos de los porteños entre el 1 de septiembre de 1802 y el 11 de febrero de 1807, con un período de interrupción durante las invasiones inglesas; fueron publicados 218 números, dos suplementos y cuatro ejemplares extraordinarios.

$\underline{9}$ Vieytes era "el típico exponente del polígrafo finicolonial, transitó la economía política, la economía doméstica (en particular la aplicada al ámbito rural), la química, la historia y la geografía, la historia natural, la agricultura, el derecho y la filosofía política” (Martínez, 2012). 
10 Foronda, V. “Carta VI”, Cartas sobre la policía, 161, tomado de Carzolio (2009).

11 Las "librerías" se trataban en realidad de bibliotecas personales, con la particularidad de que se caracterizaban por un intenso préstamo de obras -también denominado "redes de lectores"- entre familiares, amigos y conocidos. Un ejemplo paradigmático es la biblioteca particular circulante que instrumentó Facundo de Prieto y Pulido para beneficio de sus allegados -cuya circulación asentó puntillosamente en su Quaderno de los libros que me an llevado prestados-, y que luego fuera donada al convento de la Merced, dando así lugar a un nuevo tipo de establecimiento: la biblioteca pública conventual. Según el registro del Quaderno, alrededor del 50 \% de las obras prestadas estaban escritas en lengua española (Parada, 2002, 2007).

12 Podemos mencionar la traducción que Belgrano hizo de las Máximas de Quesnay, fechada en Madrid en 1794, las Lecciones de comercio de Genovesi, traducidas y glosadas por Victorián de Villava en 1784, y la Ciencia de la legislación de Filangieri, por Jaime Rubio en 1787 (Fernández Armesto, 2005).

13 Origen de los autores de obras económicas: Españoles 35, Campomanes 18, Ward 5, Arriquívar 3, Foronda 3, Uztáriz 2, Campillo 2, Sempere y Guarinos 2, Italianos 8, Filangieri 3, Genovesi 5, Franceses 7 , Mirabeau 3, Quesnay 1, Montesquieu 1, Condillac 2, Escoceses 2, Smith 2 (Fernández Armesto, 2005).

14 Entre 1788 y 1789 Foronda publicó veinte cartas sobre materias económicas y penales en el periódico Espíritu de los mejores diarios literarios que se publican en Europa. Según el inventario realizado al fallecer Juan Hipólito Vieytes, del cual conocemos sobre todo su predilección por el pensamiento de Adam Smith y otros exponentes de la ilustración escocesa, éste poseía doce tomos de esta publicación en su biblioteca personal (Torre Revello, 1940). Véase también el trabajo de Ricardo Manuel Rojas sobre el pensamiento económico de Juan Hipólito Vieytes.

$\underline{15}$ Cuando en el siglo XVIII la ganadería se valorizó enormemente por la exportación de cueros, la legislación acentuó su proteccionismo a ese sector en detrimento de la agricultura. Ésta era aún una industria exclusivamente de carácter suburbano, destinada más que nada a satisfacer las necesidades alimentarias locales (Weinberg, 1956).

16 En el Telégrafo se hacen propias las palabras del Teatro Crítico de Feijoo, al que ponderan como un Ilustrísimo Sabio Español, donde se dice: “es preciso, é importantísimo, y aun absolutamente necesario mirar con especial atención por esta buena gente [por los labradores], tomando los medios mas oportunos, para promover sus conveniencias, y mirar sus gravámenes”. (Telégrafo núm. XVIII, 30/5/01, pp. 176-177).

17 A las ya mencionadas Máximas generales del gobierno económico de un reyno agricultor de François Quesnay, se le suman la traducción de otros textos fisiocráticos en Buenos Aires en 1796, titulándolos Principios de la ciencia económico-política.

18 “El tipo de explotación agraria que tenían en mente los fisiócratas, vinculada en gran medida a los farmers que operan a gran escala y con fuerte componente de trabajo asalariado, y compararla con esa intención de incentivar el desarrollo de los pequeños y medianos "labradores” que aparece en la mayoría de los escritos ilustrados rioplatenses. Nuevamente, ésta será otra de las características comunes a los ilustrados españoles y, por tanto, de diferencia con los fisiócratas, su crítica a la gran propiedad pues llevaba a la separación de dominio y cultivo” (Pastore y Calvo, 2005).

$\underline{19}$ El comercio exterior debía regirse por los mismos principios; abogaba por una libre exportación salvo en lo referente a los granos, por lo menos, hasta que el desarrollo del sector convirtiera a España en país excedentario de los mismos, ya que como él mismo señalaba, la agricultura española estaba "en un estado progresivo de aumento" (Jovellanos, p. 69). 
$2 \underline{0}$ Hemos podido constatar que este extracto corresponde a un artículo titulado carta de un Guipuzcoano a dos paisanos suyos aparecido en el Espíritu de los mejores diarios, núm. 185 del 15/6/89.

$\underline{21}$ A pesar de ello, señala que el historiador escocés William Robertson en su Historia de América publicada en 1777, trató de "alertar a las potencias europeas por haber observado que no hay Español que no guste, y tenga en su estante la Industria y educación popular de Campomanes. (Indirecto, pero digno elogio del raro sabio, que dando el primer impulso puso en arreglado movimiento nuestra industria.) Esto, según Robertson prueba que ya en España hay más ilustración, que la que conviene á los intereses de las demás Potencias” (Semanario núm. XVII, 12/1/03, 133). Otro ejemplo que recorre similares argumentos es el artículo “Industria” del Semanario núm. XXXVI (p. 285).

$\underline{22}$ En un artículo sobre minería, Cabello y Mesa hace un exhorto a la creación de una Escuela de Mineralogía para la región (Telégrafo T. IV, núm. XV, 8/8/02, p. 540). La referencia a la Sociedad Bascongada de los Amigos del País como modelo a seguir que se realiza en dicho artículo no es casual. Éste posee varias expresiones utilizadas en el Proyecto de una escuela patriótica presentado a la Junta General de la Real Sociedad Bascongada de los Amigos del País por su Junta de Institución a 17 de septiembre de 1775.

$\underline{23}$ La práctica de los premios fue una constante en las Academias y Sociedades del mundo hispánico, tal como lo propugnaba Campomanes, y tenía el objetivo de estimular así el progreso y los adelantos entre los estudiantes y socios.

24 Sobre la enseñanza de oficios mecánicos durante el Virreinato del Río de la Plata véase la tesis de maestría de Nicolás de Arata (2010).

$\underline{25}$ También recurre Santo Tomás: "la observancia de las Leyes civiles es una obligación que trasciende el fuero de la conciencia, y que su infracción es un atentado indirecto contra la misma Ley eterna de Dios”. (Telégrafo t. I, núm. XVII, 27/5/01, pp. 161-163).

$\underline{26}$ Esta misma carta se reproduce en el periódico madrileño El regañón general o tribunal catoniano: de literatura, educación y costumbres núm. 56-57 del 14/7/04 y 18/7/04.

$\underline{27}$ Jovellanos recordaba que la soberanía real estuvo históricamente, en los periodos visigóticos, asturiano y castellano, limitada por los Concilios primeramente y luego por las Cortes. La costumbre de reunirlas fue bastante olvidada por los Borbones, quienes sólo convocaban a los diputados para el juramento de los nuevos monarcas.

$\underline{28}$ Foronda (1789), Carta I, pp. 101-02, tomado de Fernández López.

\section{Bibliografía}

\section{Fuentes primarias}

\section{Periódicos:}

Telégrafo Mercantil [Buenos Aires], 1 de abril de 1801-17 de octubre de 1802, reproducción digital.

Semanario de Agricultura [Buenos Aires] 1de septiembre de 1802-11 de febrero de 1807, reproducción digital.

Espíritu de los mejores diarios europeos [Madrid], 15 de junio de 1789, reproducción digital.

El regañón general o tribunal catoniano: de literatura, educación y costumbres [Madrid], 14 de julio de 1804-18 de julio de 1804, reproducción digital. 


\section{Documentación primaria impresa:}

Belgrano, M. (1814). Autobiografía. En B. Mitre (1857). Historia de Belgrano y de la Independencia Argentina. Buenos Aires: Editorial Juventud Argentina.

Jovellanos, G. (1859). Obras publicadas e inéditas. Madrid: B. A. E.

Rodríguez de Campomanes, P. (1774). Discurso sobre el fomento de la industria popular. Madrid: Imprenta de Antonio Sancha.

Rodríguez de Campomanes, P. (1775). Discurso sobre la educación popular de los artesanos y su fomento. Madrid: Imprenta de Antonio Sancha.

\section{Fuentes secundarias}

Arata, N. (2010). La enseñanza de oficios mecánicos durante el Virreinato del Río de la Plata (1776-1810). Buenos Aires: Libros Libres.

Caillet-Bois, R., y González J. C. (1941). Antecedentes para explicar el proceso de la clausura del Telégrafo Mercantil, el primer periódico impreso bonaerense. Revista de Historia de América, 12, 99-120.

Carzolio, M. I. (2009). Entre lo privado y lo público: las Cartas sobre la Policía de Valentín de Foronda. Ponencia presentada en XII Jornadas Interescuelas-Departamentos de Historia, Bariloche, Argentina.

Chiaramonte, J. C. (1989). La Ilustración en el Río de la Plata. Cultura eclesiástica y cultura laica durante el Virreinato. Buenos Aires: Puntosur.

Chiaramonte, J. C. (1997). Ciudades, provincias, Estados: Orígenes de la Nación Argentina (1800-1846). Buenos Aires: Ariel.

Chiaramonte, J.C. (2010). Fundamentos intelectuales y políticos de las independencias. Notas para una nueva historia intelectual de Iberoamérica. Buenos Aires: Teseo.

Díaz, C. (2012). Comunicación y Revolución, 1759-1810. La Plata: EPC.

Domínguez Ortiz, A. (2005). Carlos III y la España de la Ilustración. Madrid: Alianza.

Fernández Armesto, M. V. (2005). Lectores y lecturas económicas en Buenos Aires a fines de la época colonial. Información, cultura y sociedad, 13, 29-56.

Fernández López, M. (2006). Cartas de Foronda: su influencia en el pensamiento económico argentino. Ponencia presentada en XLI Reunión Anual de la Asociación Argentina de Economía Política, Salta, Argentina.

Goldman, N. (2012). La ciudad letrada (1776-1820). En R. Fradkin (Coord.), Colección Historia de la Provincia de Buenos Aires (pp. 297-319). Buenos Aires: Universidad Pedagógica Provincial.

Halperín Donghi, T. (1961). Tradición política española e ideología revolucionaria de mayo. Buenos Aires: Eudeba.

Halperín Donghi, T. (1972). Revolución y guerra. Formación de una elite dirigente en la Argentina criolla. Buenos Aires: Siglo XXI.

Llombart, V. (2012). Ni teoría sin aplicación, ni aplicación sin teoría: Economía política y realismo en Jovellanos. Revista asturiana de economía, 45, 7-31. 
Martínez, P. (2009). El pensamiento agrario ilustrado en el Río de la Plata: un estudio del Semanario de Agricultura, Industria y Comercio (1802-1807). Mundo agrario 9(18), 1-33.

Martínez, P. (2012). Autores y publicistas entre la colonia y la Revolución de Mayo. En M. Alabart; M. A. Fernández; M. Pérez (eds.), Buenos Aires, una sociedad que se transforma. Buenos Aires: Prometeo.

Martínez Gramuglia, P. (2012). Nuevos textos, nuevos (y viejos) lectores: la representación del público en los periódicos desde 1801 hasta 1810. En G. Batticuore y S. Gayol (eds.). Lecturas de la cultura argentina 1810-1910-2010 (pp. 24-41). Buenos Aires: Prometeo.

Martini, M. (1998). Francisco Antonio Cabello y Mesa, un publicista ilustrado de dos mundos (1786-1824). Buenos Aires: Universidad del Salvador.

Morelli, F. (2006). Tras las huellas perdidas de Filangieri: nuevas perspectivas sobre la cultura política constitucional en el Atlántico hispánico. Historia contemporánea, 33, 431-462.

Morelli, F. (2007). Filangieri y la "Otra América”: historia de una recepción. Revista Facultad de Derecho y Ciencias Políticas, 37(107), 485-508.

Navarro Floria, P. (1989). Ilustración y radicalización ideológica en el Consulado de Buenos Aires (17551810). Revista de Indias, 49(186), 411-422.

Parada, A. (2002). De la biblioteca particular a la biblioteca pública: libros, lectores y pensamiento bibliotecario en los orígenes de la Biblioteca Pública de Buenos Aires, 1779-1812. Buenos Aires: Errejotapé.

Parada, A. (2007). Cuando los lectores nos susurran: Libros, lecturas, bibliotecas, sociedad y prácticas editoriales en la Argentina. Buenos Aires: UBA.

Pastore, R. (2002). El pensamiento económico rioplatense y sus vínculos con el debate económico en la España ilustrada. Actas del Encuentro "El libro en el protopaís”.

Pastore, R., y Calvo N. (2000). Cultura colonial, ideas económicas y formación superior 'ilustrada’ en el Río de la Plata. El caso de Manuel Belgrano. Prohistoria, 4, 27-57.

Pastore, R., y Calvo N. (2005). Ilustración y economía en el primer periódico impreso del Virreinato del Río de la Plata: el Telégrafo Mercantil (1801-1802). Bulletin Hispanique, 107-2, 433-462.

Rojas, R. M. (2010). El pensamiento económico de Juan Hipólito Vieytes. Buenos Aires: Fundación San Antonio.

Sarrailh, J. (1974). La España ilustrada de la segunda mitad del siglo XVIII. México: FCE.

Torre Revello, J. (1940). El libro, la imprenta y el periodismo en América durante la dominación española. Buenos Aires: FFyL, Instituto de Investigaciones Históricas.

Weinberg, F. (1956). Estudio preliminar. En J. H. Vieytes, Antecedentes económicos de la Revolución de Mayo, Buenos Aires: Raigal. 7-133. 